\title{
Genetic Status of Monokaryotic Variants of the Wheat Stem Rust Fungus Isolated from Axenic Culture
}

\author{
By D. J. MACLEAN*, I. C. TOMMERUP† AND K. J. SCOTT* \\ Agricultural Research Council, Unit of Developmental Botany, Cambridge $C B 3 \circ D Y$, \\ Department of Botany, University of Queensland, Queensland 4067, Australia \\ and Department of Agricultural Chemistry, University of Sydney, New South Wales 2006, \\ Australia
}

(Received 3 May 1974)

SUMMARY

Cytological aspects of monokaryotic variants produced by axenic cultures of Puccinia graminis Pers. f.sp. tritici Erikss. \& E. Henn. were studied. Mitotic nuclei of variants at the end of stage I of division (late prophase to metaphase) contained approximately the same number of chromatinic bodies as haploid nuclei in dikaryotic hyphae of the parental wild type. However, an examination of spores produced by pathogenic variants showed that the size of uredospores and teliospores, the number of nuclei per spore cell, and the size of nuclei in teliospores, were all suggestive of the monokaryotic variants being diploid rather than haploid. Diploidy was also consistent with the occasional breakdown of both non-pathogenic and pathogenic monokaryons to form dikaryotic somatic cells; hyphal anastomosis was observed within one such region of dikaryotic cells produced by a non-pathogenic variant. On balance, it is concluded that nuclei in both pathogenic and nonpathogenic monokaryotic variants are diploid, and that mitotic chromosome counts do not distinguish between haploid and diploid nuclei. Diploidy is discussed in relation to naturally occurring monokaryotic rust fungi and to somatic variation in populations of dikaryotic rusts.

\section{INTRODUCTION}

Following the initial isolation of axenic cultures of Puccinia graminis Pers. f.sp. tritici Erikss. \& E. Henn. from uredospores, a number of distinct mycelial types have been recognized (Williams, Scott, Kuhl \& Maclean, I967; Maclean \& Scott, 1970; Williams, 197I). As these cultures should prove useful material for biochemical studies, as well as providing new possibilities for rust genetics, it is important to establish the genetic status of each mycelial type. Of particular interest are the monokaryotic variants which arose at a low incidence from densely seeded cultures in which the majority of sporelings failed to grow (Scott \& Maclean, I969; Maclean \& Scott, I970; Maclean, I974), or as sectors from ' primary mycelium' (Williams \& Hartley, I97I). These variants resembled the dikaryotic primary mycelium in forming a substantial thallus, but differed from primary mycelium by remaining viable for extended periods of time; hence, in earlier publications the variants were termed 'persistently vegetative isolates' (Maclean \& Scott, 1970) or 'continuously subculturable, uninucleate lines' (Williams \& Hartley, I97I). Monokaryotic variants differ in pathogenicity

\footnotetext{
* Present address: Department of Biochemistry, University of Queensland, Australia.

$\uparrow$ Present address: Unit of Developmental Botany, Cambridge.
} 
on wheat (Maclean \& Scott, 1974). On rare occasions, monokaryotic variants formed dikaryotic hyphae, and Maclean (1974) isolated a stable dikaryotic variant which could be readily subcultured.

The main purpose of this paper is to consider the genetic status of monokaryotic variants. Although chromosome counts are the traditional method of determining the ploidy of mitotic nuclei in most organisms, previous reports on the number of chromosomes in monokaryotic variants of $\boldsymbol{P}$. graminis differ, with Maclean, Scott \& Tommerup (1971) favouring haploidy, and Williams \& Hartley (197I) favouring diploidy. To resolve this difference, we have made a close study of mitosis at the end of stage I of division (late prophase to metaphase) in mycelium of monokaryotic variants, a dikaryotic variant, and the parental wild type.

Other observations bearing on the genetic status of monokaryotic variants (spore size, nuclear size, dikaryotization and anastomosis) are presented and discussed in relation to chromosome counts, and we now believe that monokaryotic variants are diploid. Our conclusions are discussed in relation to the possible occurrence of somatic diploids in natural populations of rust fungi.

\section{METHODS}

Growth of cultures. Variant strains of $P$. graminis Pers. f.sp. tritici Erikss. \& E. Henn. were isolated from race $\mathrm{I}$ 26-ANZ-6,7 (referred to as the wild type) and maintained as described previously (Maclean \& Scott, 1970; Maclean, I974). Strains VIA, V2A, V2B, V2C, V2D and V4 were monokaryotic and non-pathogenic (Maclean \& Scott, 1974). Four strains, viB, vIC, V3A (all monokaryotic) and V3B (dikaryotic) were pathogenic and were induced to sporulate by infecting wheat leaves with axenically grown mycelium (Maclean \& Scott, 1974). Infections of the wild type, and strain VIC on some occasions, were established with uredospores as described by Maclean et al. (197I). The development of teliospores of race 126-ANZ-6,7 on seedling leaves of wheat is suppressed, and we are grateful to Dr P. G. Williams for allowing us access to fully grown infected plants for collection of the wild-type teliospores described in Table 2 below.

Cytological techniques. For cytological examination, small pieces (approx. $\mathrm{I} \mathrm{mm}^{2}$ ) of mycelium grown on agar medium (medium II or IV, Maclean, I974) or in wheat leaves (Maclean et al. 1971; Maclean \& Scott, 1974) were fixed in LAA (lactic acid + acetic aci + p ethanol, I : I :6, by vol., Maclean et al. 197I), or modified Helly solution (Robinow \& Caten, I969), or $6 \%$ glutaraldehyde in cacodylate buffer (Sargent, Tommerup \& Ingram, I973). After fixation, material was hydrolysed with $\mathrm{I} \mathrm{N}$-hydrochloric acid for 6 to $8 \mathrm{~min}$ at $60^{\circ} \mathrm{C}$, or $5 \mathrm{~N}$-hydrochloric acid at 20 to $23{ }^{\circ} \mathrm{C}$ for $20 \mathrm{~min}$ (to differentiate the spindle), or $45 \mathrm{~min}$ (to differentiate chromatin), then stained with Giemsa's fluid (Tommerup \& Langdon, 1969), or propionic iron haematoxylin (Tommerup \& Ingram, 197I), or with Feulgen. Material to be stained with acid fuchsin (Robinow \& Caten, 1969) was fixed with Helly or glutaraldehyde immediately (within $\mathrm{I} \mathrm{h}$ ) before staining. During mounting, material was teased out and was usually heavily squashed.

To observe nuclear division in living hyphae, small tufts of aerial mycelium were dissected. with minimal damage from colonies grown on agar medium and mounted in water. Nuclei were illuminated with either bright field or phase contrast for periods of 10 to $30 \mathrm{~s}$, and were examined at intervals of 5 to $30 \mathrm{~min}$.

Aithough nuclei could readily be discerned in immature uredospores and teliospores stained with Giemsa, results were often unsatisfactory using older spores. However, nuclei in older teliospores could be readily discerned by mounting living preparations in water and 
observing with phase contrast microscopy. Nuclei could sometimes be seen in mature uredospores mounted in water, using bright-field or phase contrast microscopy.

\section{RESULTS}

\section{Nuclear division}

In describing the stages of division we will use the terminology of Robinow \& Caten (1969). As there are conflicting opinions in the literature on the interpretation of mitotic division figures in fungi, it was necessary to determine the chromatinic distributions during division, so that the end of stage I could be identified and the number of stained bodies counted.

In living hyphae, the sequence of events during division of individual nuclei appeared to be the same in strains VIC, V2A and V3A (monokaryons), and V3B and the wild type (dikaryons). During stage I of division, the oval resting nucleus slowly contracted and became more or less spherical. The later stages of division were characterized by rapid elongation of the spherical daughter nuclei which expanded to form oval resting nuclei.

Using material stained with acid fuchsin, the mitotic fibre (intranuclear spindle) was first visible as a short rod within the periphery of contracting nuclei, and moved to a more central position when the nucleus was most highly contracted (see Robinow \& Caten, I969, for Aspergillus nidulans). During stage II of division the fibre expanded along the axis of the elongating nucleus, but was not visible in daughter nuclei; the frequency of these elongated spindles was very low. To correlate the length of the spindle (which indicated the stage of division) with the chromatinic distribution, nuclei which had been stained with acid fuchsin were hydrolysed with $5 \mathrm{~N}$-hydrochloric acid at room temperature $(20 \mathrm{~min})$ then stained with propionic iron haematoxylin. Using this procedure, both the spindle and the chromatin were weakly stained. The faintly stained chromatinic arrangements were then compared with nuclei stained with propionic iron haematoxylin (45 min hydrolysis), with Giemsa, or with Feulgen - each method gave similar division figures. The clearest chromatinic distributions were seen in nuclei stained with Giemsa. All strains listed in Methods were examined after staining with Giemsa.

The chromatin in resting phase nuclei was arranged as a granular reticulum (Figs. I, 4, I I and I3). During stage I of division (prophase-metaphase) the nuclei contracted and the chromatin condensed into discrete bodies (Figs. 2, 3, 5, 6 and $8 a$ ). At the end of stage I approximately six distinct chromatinic bodies could be seen in nuclei of both dikaryotic (Figs. 7 and 8) and monokaryotic (Figs. 9 and Io) cells. In stage II (early anaphase) the chromatinic bodies separated to form what appeared to be two more or less parallel chains. Stage III was characterized by the movement of chromatinic bodies from daughter chains to opposite poles of the spindle (Fig. 12) where the chromatin coalesced (Fig. 14). The chromatin of the two daughter nuclei gradually became more granular during stage IV. No differences could be discerned between individual nuclei in monokaryons or dikaryons at any stage of division.

\section{Uredospore morphology and cytology}

The dimensions $(\mu \mathrm{m})$ of living uredospores mounted in water were in the following ranges: VIC, I8-33 $(24 \pm 3) \times 24-48(33 \pm 4)$; wild type, I7-25 $(20 \pm 4) \times 25-43(34 \pm 2)$; parentheses give the mean \pm standard deviation.

Uredospores of VIC were slightly more rounded than the wild type (Figs. I5, I6, I9). A comparison of volumes (Fig. 24) showed that VIC and the wild type gave overlapping 
Genetics of monokaryons of wheat stem rust

367

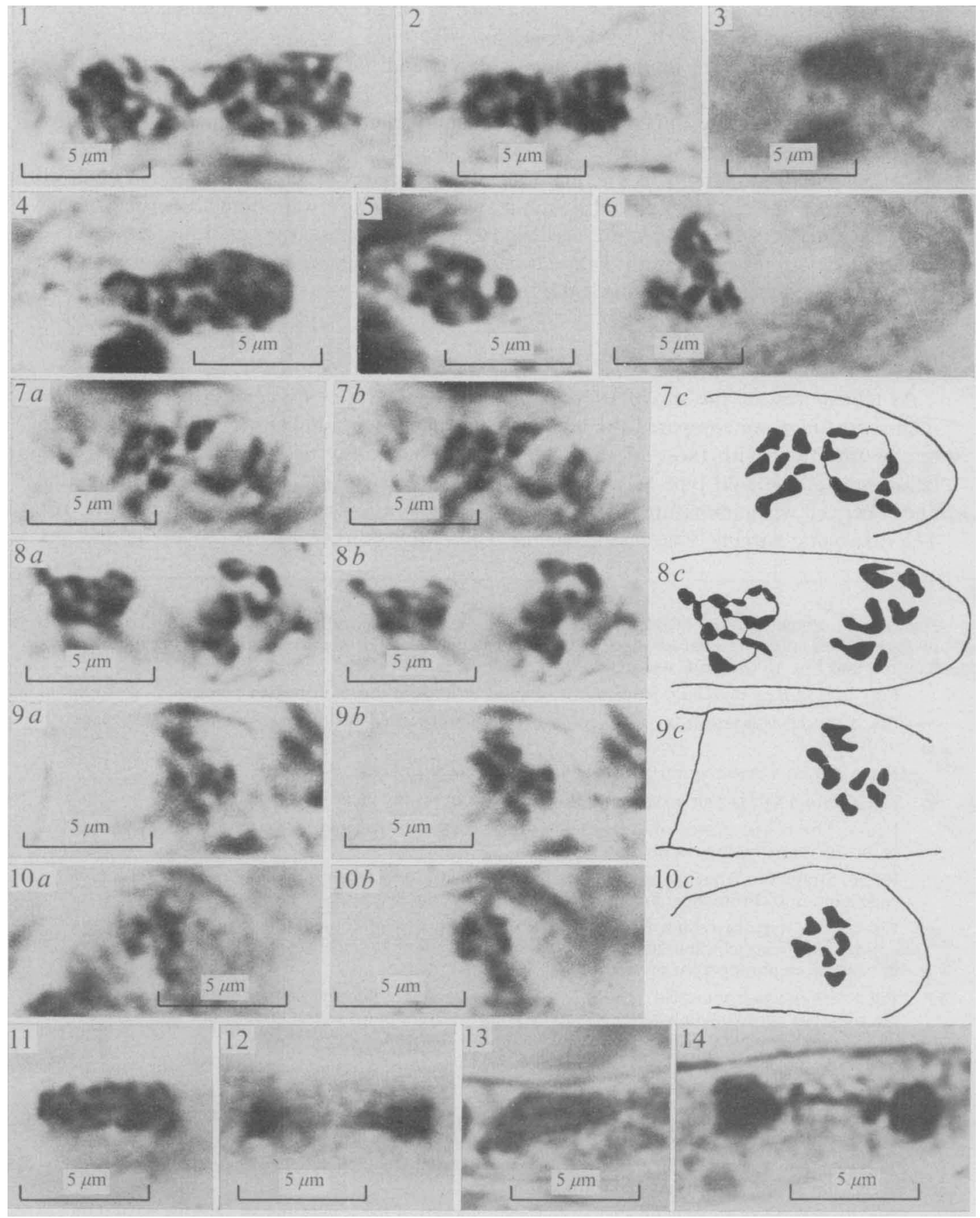


frequency distributions; the mean volume of VIC uredospores was significantly greater $(P=0.001)$ than that of the wild type (VIC: wild type $=9960 \mu \mathrm{m}^{3}: 7520 \mu \mathrm{m}^{3}=\mathrm{I} \cdot 3: 1$ ) . Uredospores of VIC were more variable in volume, and populations often contained a low incidence of giant spores (Figs. 19, 24).

Although nuclei were difficult to discern in mature uredospores stained with Giemsa, preparations of immature spores showed that uredospores of the wild type had the expected dikaryotic condition (Fig. 17). The majority of uredospores of VIC were uninucleate at all stages of development (Fig. 20), although a small proportion were binucleate (about $3 \%$; cf. Maclean et al. 197I). In mature uredospores of VIC, the nuclear condition could sometimes be determined by bright-field illumination: normal-sized spores appeared to be uninucleate and giant spores binucleate.

\section{Teliospore morphology and cytology}

As teliospores are the site of karyogamy in wild isolates of Puccinia graminis and most other rust fungi, we compared the teliospores formed by a number of variant strains with one another and with those of the wild type. As previously described (cf. Buller, 1950), teliospores of the wild type arise from a mycelial dikaryophase, and contain two haploid nuclei per cell when immature (Fig. 15), and a diploid fusion nucleus in older cells (Fig. I6). The dikaryotic variant, v3B, resembled the wild type in this respect (Figs. 33, 34 and 35).

Figs. I to I4. Somatic nuclei of dikaryotic (strain v3B, the wild type) and monokaryotic (strain vic) isolates of Puccinia graminis. Material was fixed in LAA and stained with Giemsa, except for Fig. 3 (glutaraldehyde fixation) and Fig. Io (Feulgen staining).

Fig. I. Wild-type mycelium from wheat; conjugate haploid nuclei in resting phase.

Fig. 2. Strain v3B grown on agar: conjugate (haploid) nuclei showing contraction at early stage of division.

Fig. 3. Strain v3B grown on agar: nuclei at same stage as Fig. 2.

Fig. 4. Strain vIC grown on agar: (diploid) nucleus in resting phase.

Fig. 5. Strain VIC grown on agar: (diploid) nucleus showing contraction and condensation of chromatin at early stage of division.

Fig. 6. Strain VIC from wheat: very heavily squashed (diploid) nucleus showing condensation of chromatin into chromatinic bodies towards the end of the first stage of division.

Fig. 7. Wild-type mycelium from wheat. (a), (b) Two foci of conjugate haploid nuclei showing approximately six chromatinic bodies at the end of the first stage of division. (c) A composite drawing from photographs of several levels of focus.

Fig. 8. Strain v3B from wheat. (a), (b) Two levels of focus of conjugate (haploid) nuclei. Nucleus on the right has approximately six chromatinic bodies at same stage as both nuclei in Fig. 7; nucleus on left is at the same stage as Fig. 5. (c) A composite drawing.

Fig. 9. Strain vic from wheat. (a), (b) Two levels of focus of a (diploid) nucleus showing approximately six chromatinic bodies at same stage as Fig. 7. (c) A composite drawing.

Fig. IO. Strain vic grown on agar. (a), (b) Two foci of a (diploid) nucleus showing approximately six chromatinic bodies at same stage as Fig. 7. (c) A composite drawing.

Fig. I I. Strain V3B grown on agar. A (haploid) nucleus of the conjugate pair showing fine granular chromatin at resting phase, unsquashed preparation.

Fig. 12. Strain V3B growing on agar. A (haploid) nucleus of the conjugate pair showing separation of condensed chromatinic bodies at the end of the middle phase of division.

Fig. 13. Strain vic grown on agar. A (diploid) nucleus showing fine granular chromatin at resting phase, unsquashed preparation, cf. Fig. 1 I.

Fig. 14. Strain VIC from wheat. A (diploid) nucleus showing separation of two condensed masses of chromatin during late stage of division. 


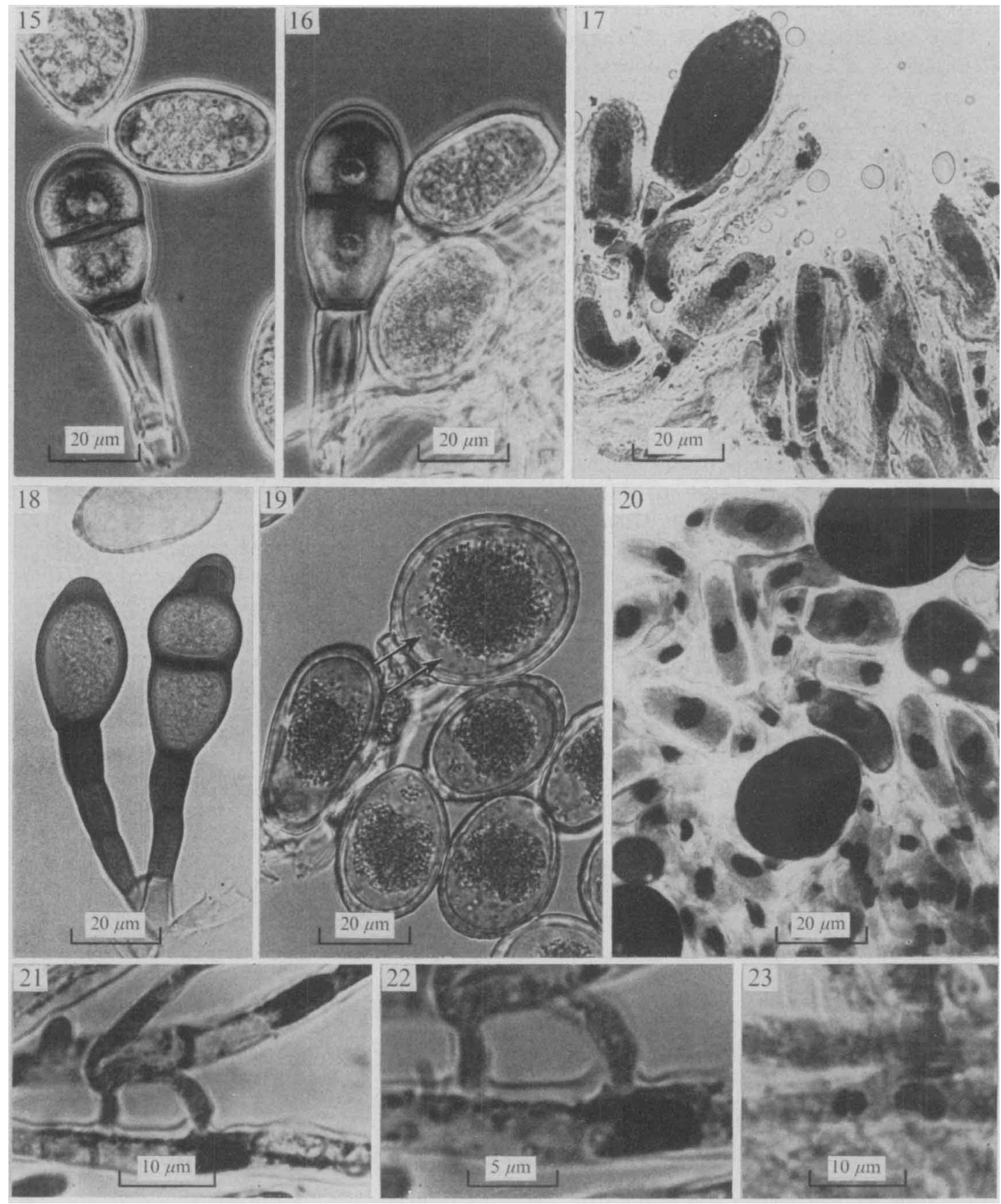


However, teliospores of the monokaryotic variants (VIB, VIC and V3A) arose from a monokaryotic mycelium (cf. Maclean et al. 1971, for strain vIC). There was no evidence for the initiation of a mycelial dikaryophase before the formation of teliospores, as is known, for example, to happen in the homothallic rust Puccinia malvacearum which has a monokaryotic somatic mycelium (Brown, 1940; Buller, 1950). The conjugate nuclei in teliospores of $P$. malvacearum eventually undergo karyogamy to form uninucleate teliospore cells.

Compared with the wild type, the variant strains produced a high proportion of unusual types of teliospores which varied in the number of cells per teliospore and the number of nuclei per teliospore cell (Figs. 26 to 31 ). To determine whether this could be due to cytological events which might indicate the genetic status of the variants, we counted the frequency of different types of teliospores present in material at various stages of development. The two most interesting features were the high incidence of teliospores which were singlecelled (Fig. 18), and the high proportion of single-celled teliospores which were binucleate (Figs. 26, 27 and 28) or even tri- or tetranucleate (Figs. 27, 29 and 30), especially in strains VIB and vic. Single-celled teliospores (sometimes called mesospores) are characteristic of the genus Uromyces, whereas two-celled teliospores are characteristic of Puccinia, the genus of the wild type. Some of our counts, which indicate the frequency of different types of teliospore, are summarized in Table I. In contrast to the variant strains, very few samples of the wild type contained any Uromyces-type teliospores.

The high proportion of binucleate cells observed in Uromyces-type teliospores of the monokaryotic variants VIB and VIC, could indicate that a dikaryophase was initiated within these teliospores. However, we could find no direct evidence that nuclei in such teliospores subsequently underwent karyogamy. Furthermore, it was clear (cf. Figs. 26 to 30) that teliospore cells containing two or more nuclei were larger than uninucleate cells. We therefore believe that the binucleate teliospore cells arose as a result of septa failing to form during sporogenesis. This view is also supported by measurements of the size of nuclei (see below).

Figs. I5 to 20. Uredospores and teliospores produced on wheat by race 126-ANZ-6,7 and strain VIC of Puccinia graminis f.sp. tritici.

Figs. 15 and 16 . Phase-contrast micrographs of uredospores and teliospores of race 1 26-6,7 mounted in water. Teliospore cells contain two small, haploid, pre-fusion nuclei (Fig. I5) or a large diploid fusion nucleus (Fig. I6).

Fig. 17. Frozen section of uredial sorus of race 1 26-6,7 stained with Giemsa, showing the binucleate condition of developing spores.

Fig. 18. Single-cell (Uromyces-type) and two-cell (Puccinia-type) teliospores of vic mounted in lactophenol.

Fig. 19. Living uredospores of VIC mounted in water; two nuclei could be seen in the giant uredospore in the positions indicated by the arrows.

Fig. 20. Frozen section of uredial sorus of strain vIC stained with Giemsa, showing the uninucleate condition of developing spores.

Figs. 2 I to 23. Hyphae found in a small sector within a colony of strain v2A; the preparations were stained with Giemsa and squashed.

Fig. 21. Anastomoses between a narrow fusion hypha and a monokaryotic hypha of apparently normal size.

Fig. 22. Same object as Fig. 21, but at a different focus and higher magnification to show continuity between hyphae at the two points of anastomosis.

Fig. 23. Subapical region of a dikaryotic hypha, showing nuclei just after conjugate division. The dikaryotic cells arose from a monokaryotic hypha of apparently normal dimensions after anastomosis with a narrow tube. 

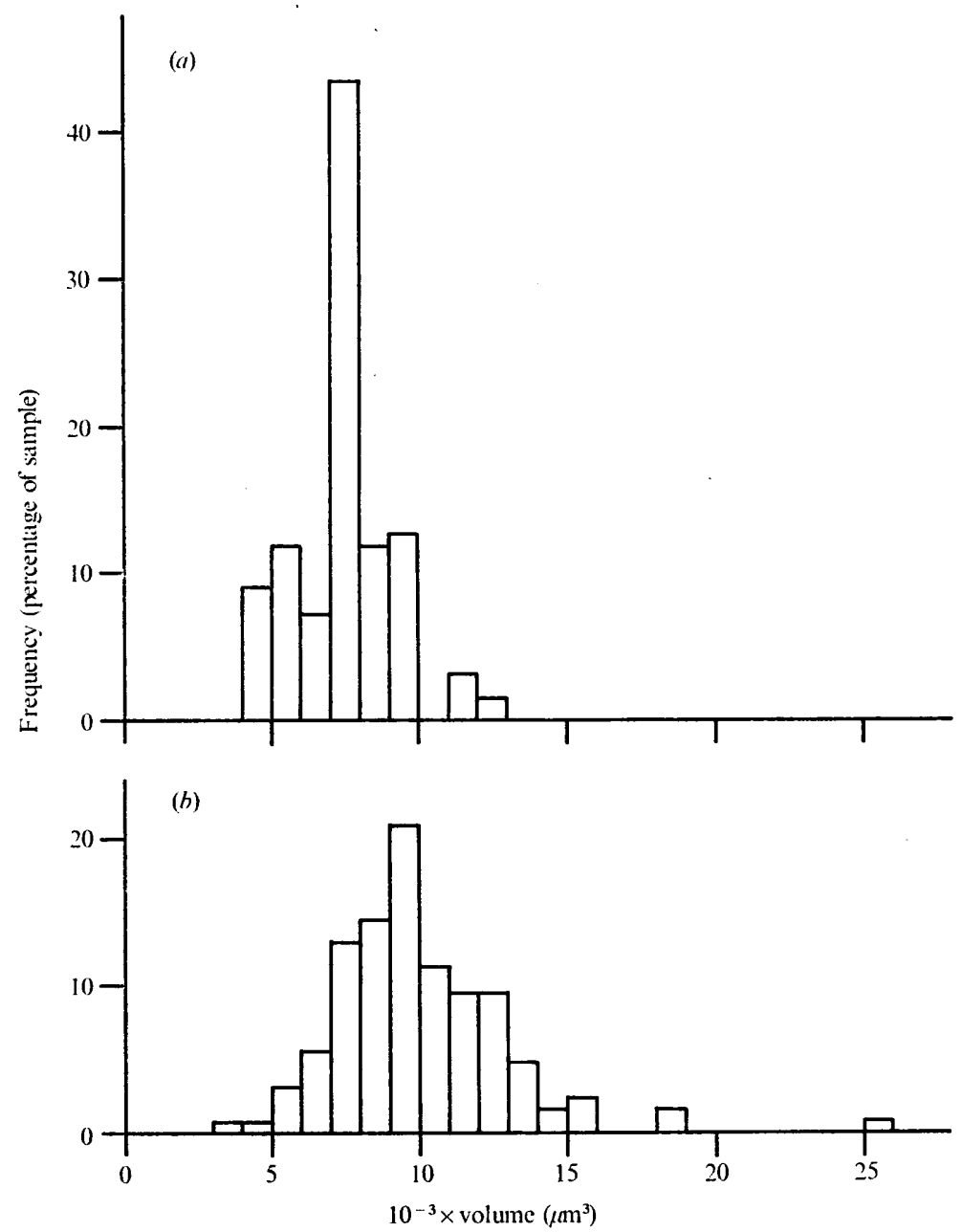

Fig. 24. Frequency distribution of volume of uredospores of (a) the wild type and $(b)$ strain viC of Puccinia graminis. Uredospores of both strains were collected from wheat leaves infected by inoculation with uredospores. Uredospores were measured when mounted in water; assuming an ellipsoid shape, volumes were calculated from the formula (Lamb, 196I):

$$
\text { volume }=\frac{4}{3} \pi\left[\left(\frac{\text { width }}{2}\right)^{2} \times\left(\frac{\text { length }}{2}\right)\right] .
$$

Sample sizes were: VIC, 55 spores; wild type, 124 spores.

\section{Size of nuclei in teliospores}

Using phase-contrast microscopy of living preparations, the diameter of nuclei was determined in teliospores of the wild type, one dikaryotic variant, and three monokaryotic variants. The mean diameter of nuclei in teliospores grouped according to Table 2 fell into two distinct categories: small $(3.4$ to $3.5 \mu \mathrm{m})$ or large $(4.8$ to $5.3 \mu \mathrm{m})$. Tests for significance showed that differences between any two sets of small nuclei, or any two sets of large nuclei, were not significant. However, the difference between any set of small nuclei and any set of large nuclei was highly significant $[P<0.001$; assuming that nuclei were spherical, volume 
ratio small:large $\left.=(2 \mathrm{I}-23) \mu \mathrm{m}^{3}:(58-78) \mu \mathrm{m}^{3}\right]$. Small nuclei were found only in binucleate cells of teliospores of the dikaryotic strains v3B and race $126-6,7$ (Figs. I 5, 34 and 35). The fusion nuclei in uninucleate spore cells of these strains were large (Figs. I6, 34 and 35), as were all nuclei in both uninucleate and binucleate spore cells of the monokaryotic strains VIB, VIC and V3A (Figs. 25 to 32 ).

\section{Hyphal anastomosis and change in nuclear condition}

Despite much cytological examination, only on three occasions have we detected dikaryotic somatic cells in colonies of monokaryotic variants. On one occasion, strain v3A (monokaryotic) formed a stable dikaryotic variant, strain $\mathrm{v} 3 \mathrm{~B}$, which overgrew the monokaryotic culture (cf. Maclean, 1974). On the other two occasions, small regions of dikaryotic cells were observed in monokaryotic colonies of strain V2A. In the dikaryotic region of one colony, a number of hyphal anastomoses were observed (e.g. Figs. 2I and 22). Figure 23 shows a portion of a dikaryotic hypha which arose from a monokaryotic hypha at the site of anastomosis with a narrow fusion tube. This colony of v2A provided the only hyphal anastomoses which we have seen in any of our variant strains (cf. Maclean, 1974).

\section{DISCUSSION}

During the discovery of the parasexual cycle in fungi the existence of an extended somatic diplophase was demonstrated unequivocally by means of genetic analysis (Roper, I966). It was subsequently found that authentic haploids and diploids could be distinguished by a number of morphological and cytological criteria. As precise genetic analyses are not yet possible with monokaryotic variants of $P$. graminis tritici, and the mechanism(s) by which they arise from the wild-type dikaryon are unknown, the ploidy of their nuclei must largely be inferred from their morphology and cytology.

Interpretation of mitosis. During mitosis, we could discern no difference in chromatinic distribution between haploid nuclei in dikaryotic cells of the wild type or strain V3B, and nuclei in cells of the monokaryotic variants VIC, V2A or V3A. The observed pattern of division appeared to be similar to that described for a number of other fungi such as Aspergillus nidulans (Robinow \& Caten, 1969) and Ustilago violacea (Day, 1972; Day \& Jones, 1972). When the chromatin was most highly contracted at the end of stage I of division, approximately six darkly staining bodies could be seen in haploid nuclei of the dikaryons. The approximate chromosome complement of six agrees with the chromosome counts of McGinnis (1953) on haploid nuclei in germinating basidiospores of $P$. graminis. An approximate number of six staining bodies was also seen in nuclei of the monokaryotic variants, which we now believe to be diploid on the basis of spore size and nuclear size, as discussed later.

Our interpretation of chromosome number in nuclei of monokaryotic variants of $P$. graminis differs from that of Williams \& Hartley (1971), who found nuclei containing about I 2 staining particles, which they interpreted as a diploid number of chromosomes at late prophase of mitosis. However, an alternative interpretation of the photograph they published is that of a nucleus at resting stage to early prophase. In our preparations, nuclei, which we believe are at resting phase to early prophase, contain granular chromatin in which about 12 relatively distinct bodies can be discerned. When such nuclei are dried (cf. Williams, I97I), the bodies fall into one plane and become more discrete and distinct. Therefore, it appears that $P$. graminis is a fungal species in which mitotic chromosome counts cannot be used to distinguish between haploid and diploid nuclei. Recent reports 


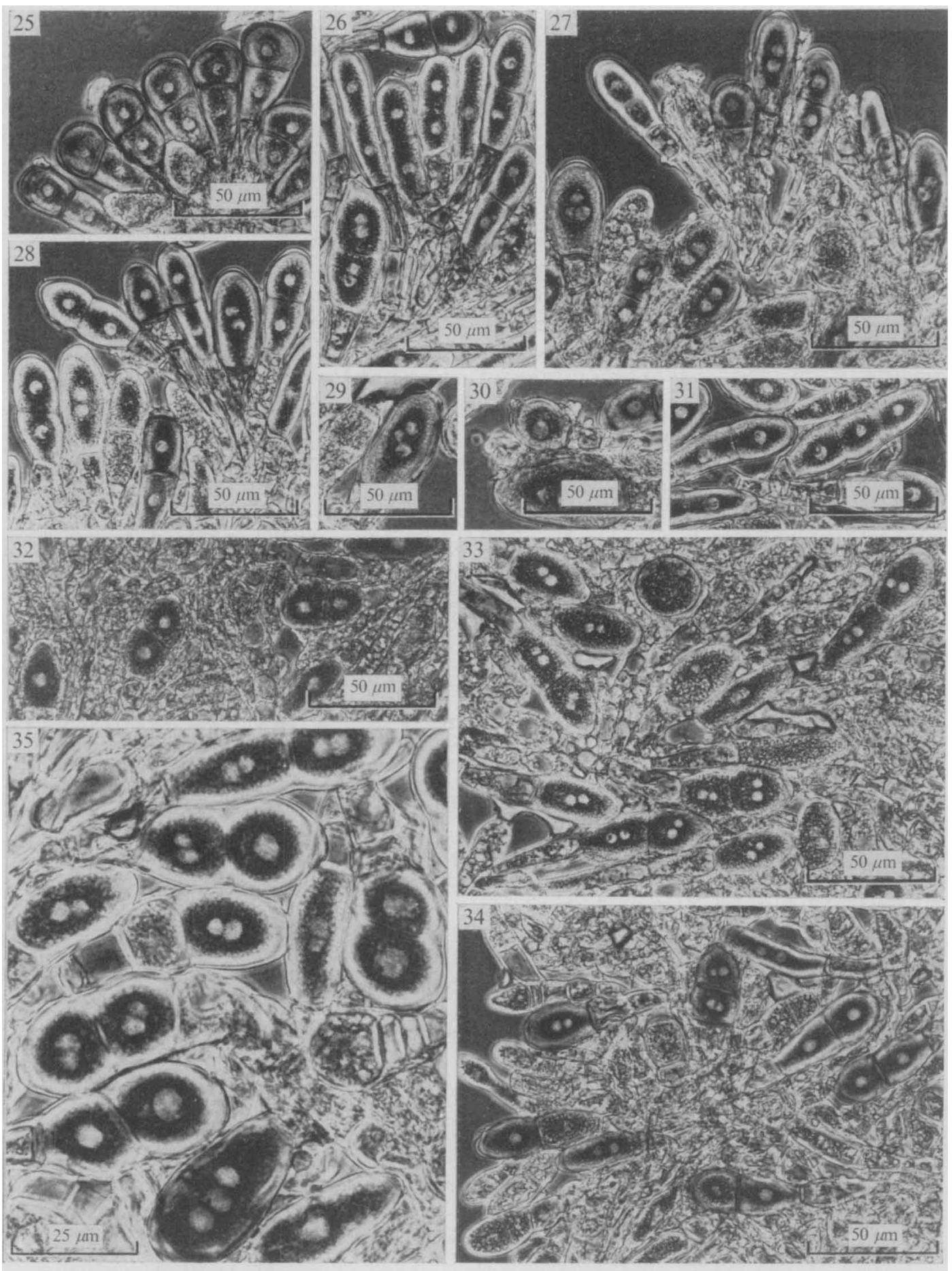


show that chromosome counts could not distinguish haploid and diploid strains of two other species of higher fungi: $A$. nidulans (Robinow \& Caten, 1969) and $U$. violacea (Day \& Jones, 1972).

Spore size. It has been shown that in homologous fungal structures, particularly spores, the volume of cytoplasm per genome is constant (Clutterbuck, 1969; Ishitani, Uchida \& Ikeda, 1956; Tinline \& MacNeill, 1969). In the present investigation the mean volume of uredospores of strain VIC of $\boldsymbol{P}$. graminis was somewhat greater than the wild type (volume ratio VIC: wild type $=1 \cdot 3: 1$ ). As uredospores of the wild type contain two haploid nuclei, the single nucleus of VIC uredospores would seem to be diploid (2n), or possibly even hyperdiploid. However, we think the latter possibility unlikely because compared with the wild type, vIC contained a higher incidence of giant binucleate uredospores (presumably $2 n+2 n$ ); furthermore VIC uredospores readily swelled and often burst when mounted in water.

Nuclear size. Nuclear size is considered a useful criterion of ploidy in fungi (Esser \& Kuenen, 1967; Tinline \& MacNeill, 1969). Under natural conditions, rust fungi produce no proven somatic diplophase with which vegetative hyphae of monokaryotic variants can be compared. Teliospores of wild isolates of $\boldsymbol{P}$. graminis are derived from the dikaryophase, and contain two haploid nuclei per cell when immature and a diploid fusion nucleus when mature. Therefore, teliospores are the only structures in which authentic haploid and diploid nuclei can be compared.

The measurements of nuclear size we have presented show that nuclei in teliospore cells of pathogenic monokaryotic variants (VIB, VIC, V3A) appear to be diploid because they were the same size as diploid fusion nuclei in wild-type teliospores. As there was no evidence that a dikaryophase was initiated at any stage of teliospore development, or that nuclear

Figs. 25 to 35. Micrographs taken under phase-contrast illumination of living teliospores of variant strains mounted in water. Note the nucleoli (dark) bodies to be seen in many of the nuclei (and in the nuclei in Figs. 15 and 16).

Fig. 25. Large nuclei in teliospores of strain vic sampled from a telial sorus 25 days after inoculating wheat leaves with uredospores.

Figs. 26 to 3I. Large nuclei in teliospores of strain VIB sampled from wheat leaves 17 to 22 days after inoculation with axenically-grown mycelium.

Fig. 26. Puccinia-type (i.e. two-cell) teliospores; note the relatively large size of the spore with binucleate cells.

Fig. 27. Uninucleate, binucleate and trinucleate teliospore cells within a single sample; note the high incidence of Uromyces-type (i.e. single-cell) teliospores which are multinucleate.

Fig. 28. Binucleate Uromyces-type teliospores of about the same size as Puccinia-type teliospores with uninucleate cells.

Figs. 29, 30. Micrographs of giant trinucleate and tetranucleate spores.

Fig. 3I. A teliospore composed of three uninucleate cells.

Fig. 32. Teliospores of strain V3A sampled 22 days after inoculating wheat leaves with axenically grown mycelium; all nuclei were large.

Figs. 33 to 35 . Teliospores of strain V3B sampled at various times after inoculating wheat leaves with axenically grown mycelium.

Fig. 33. Young teliospores, sampled 15 days after inoculation; each teliospore cell contains two small nuclei.

Fig. 34. Sample taken 18 days after inoculation; some teliospore cells contain two small nuclei, other cells contain a single large nucleus.

Fig. 35. Higher magnification of teliospores of v3в (sampled 2 I days after inoculation) to show nuclei at various stages of karyogamy. Also present is a large, aberrant, Uromyces-type trinucleate teliospore. 
Table I. Distribution of nuclei in cells of Uromyces-type and Puccinia-type teliospores of variant strains of P. graminis

\begin{tabular}{|c|c|c|c|c|c|c|}
\hline \multirow[b]{3}{*}{ Sample number } & \multirow{3}{*}{$\begin{array}{l}\text { No. of } \\
\text { spores in } \\
\text { sample }\end{array}$} & \multirow{3}{*}{$\begin{array}{c}\text { Uromyces- } \\
\text { type } \\
\text { teliospores } \\
\text { in sample } \\
(\%)\end{array}$} & \multicolumn{4}{|c|}{ Teliospore cells containing one or two nuclei $(\%)$} \\
\hline & & & \multicolumn{2}{|c|}{$\begin{array}{c}\text { In Uromyces-type } \\
\text { teliospores }\end{array}$} & \multicolumn{2}{|c|}{$\begin{array}{l}\text { In Puccinia-type } \\
\text { teliospores }\end{array}$} \\
\hline & & & (I) & (2) & (I) & (2) \\
\hline \multicolumn{7}{|c|}{ Strain v3A (monokaryotic) } \\
\hline I & 42 & 64 & 100 & 0 & 100 & 0 \\
\hline 2 & 426 & 75 & 98 & 2 & 100 & 0 \\
\hline \multicolumn{7}{|c|}{ Strain vic (monokaryotic) } \\
\hline $\begin{array}{l}3 \\
4\end{array}$ & $\begin{array}{l}676 \\
600\end{array}$ & $\begin{array}{l}3 \mathrm{I} \\
40\end{array}$ & $\begin{array}{l}95 \cdot 7 \\
88 \cdot 5\end{array}$ & $\begin{array}{r}4 \cdot 3 \\
11 \cdot 5\end{array}$ & $\begin{array}{l}99 \cdot 7 \\
98 \cdot 5\end{array}$ & $\begin{array}{l}0.3 \\
1 \cdot 5\end{array}$ \\
\hline \multicolumn{7}{|c|}{ Strain VIB (monokaryotic) } \\
\hline $\begin{array}{l}5 \\
6\end{array}$ & $\begin{array}{l}276 \\
166\end{array}$ & $\begin{array}{l}47 \\
50\end{array}$ & $\begin{array}{l}40 \\
38\end{array}$ & $\begin{array}{l}60 \dagger \\
62\end{array}$ & $\begin{array}{r}93 \\
100\end{array}$ & $\begin{array}{l}7 \\
0\end{array}$ \\
\hline \multicolumn{7}{|c|}{ Strain v3B (dikaryotic)* } \\
\hline $\begin{array}{l}7 \\
8\end{array}$ & $\begin{array}{l}238 \\
320\end{array}$ & $\begin{array}{l}47 \\
64\end{array}$ & $\begin{array}{l}48 \cdot 7 \\
97 \cdot 0\end{array}$ & $\begin{array}{r}5 \mathrm{I} \cdot 3 \ddagger \\
3 \cdot 0 \$\end{array}$ & $\begin{array}{l}51 \\
97 \cdot 3\end{array}$ & $\begin{array}{l}49 \\
2 \cdot 7\end{array}$ \\
\hline
\end{tabular}

Spores were sampled 2 I to 34 days after inoculation and, apart from v3B, were always taken from the centre of a sorus.

* Spores taken from periphery (sample 7) and centre (sample 8) of the same sorus.

$\dagger$ Includes $3.8 \%$ trinucleate and $0.7 \%$ tetranucleate cells.

$\ddagger$ Includes $0.9 \%$ trinucleate cells.

$\$$ Includes $0.5 \%$ trinucleate cells.

Table 2. Mean diameters of nuclei in living teliospores of Puccinia graminis

\begin{tabular}{|c|c|c|c|c|c|}
\hline & \multirow{3}{*}{-} & \multicolumn{4}{|c|}{ Mean diameter ( $\mu \mathrm{m} \pm$ standard error) } \\
\hline & & \multicolumn{2}{|c|}{ Uromyces-type (one-celled) } & \multicolumn{2}{|c|}{ Puccinia-type (two-celled) } \\
\hline & & Uninucleate & Binucleate & Uninucleate & Binucleate \\
\hline vIC (monokaryon) & & $5 \cdot 3 \pm 0 \cdot I$ & - & $5 \cdot 0 \pm 0 \cdot 1$ & - \\
\hline VI B (monokaryon) & & $5 \cdot 0 \pm 0 \cdot 1$ & $4 \cdot 9 \pm 0 \cdot I$ & $5 \cdot 0 \pm 0 \cdot 1$ & $5 \cdot 0 \pm 0 \cdot 1$ \\
\hline v3A (monokaryon) & & $5 \cdot 2 \pm 0 \cdot I$ & - & $4 \cdot 8 \pm 0 \cdot 1$ & - \\
\hline v3B (dikaryon) & & $5 \cdot 3 \pm 0.3$ & $3 \cdot 5 \pm 0 \cdot I$ & $5 \cdot 3 \pm 0 \cdot I$ & $3 \cdot 4 \pm 0 \cdot 1$ \\
\hline 126-6,7 (dikaryon) & & - & - & $5 \cdot 3 \pm 0 \cdot 1$ & $3.5 \pm 0.1$ \\
\hline
\end{tabular}

Teliospores were mounted in water and observed by phase-contrast microscopy. Nuclear diameters were measured directly (race 126-6,7) or from photomicrographs. Sample sizes ranged from 8 to 185 nuclei.

fusion occurred in binucleate teliospore cells of the monokaryotic strains, we conclude that in somatic cells the nuclei were also diploid.

Dikaryotization, anastomosis and sexual incompatibility. Some of the variability which has been observed during the growth of monokaryotic variants, could have resulted from parasexual phenomena (cf. Maclean, 1974). In particular, we detected hyphal anastomoses in monkaryotic variants on one occasion, and these anastomoses were present in a small dikaryotic sector. The low frequency both of dikaryotization and hyphal anastomosis in our cultures suggests a causal relationship between these two phenomena. Dikaryotization could thus have been a result of a two-step process in which a diploid first formed haploid (or hyperhaploid) mycelia by either somatic meiosis (Ellingboe, 196I, 1964) or non- 
disjunction at mitosis (Käfer, 196I ; Roper, I966), followed by anastomosis of the $(+)$ and (-) mycelia.

If the monokaryotic variants were haploid rather than diploid, it should have been possible to isolate variants of opposite mating types which would interact sexually with each other. However, attempts to test this possibility by allowing mycelia of different strains to grow together produced no evidence of anastomosis or of dikaryon formation (Maclean, 1974). The results were consistent with nuclei in monokaryotic hyphae containing both mating factors within the same nuclear membrane, as in a diploid.

Ploidy in relation to pathogenicity of the variants. It has recently been found (G. J. Green, P. G. Williams and D. J. Maclean, unpublished) that dikaryons which are almost indistinguishable from the wild type can be obtained from uredial cultures of strain VIC. This would only seem possible if VIC were a heterozygous diploid rather than a haploid homokaryon as we first proposed (Maclean et al. 1971). The uredial culture of Maclean et al. (197I) remained monokaryotic and morphologically stable when closely examined over six successive generations; some uredial cultures of Green, Williams and Maclean broke down and became heterogeneous much sooner.

The most important evidence for diploidy has been obtained from the study (Maclean, 197I) of spores produced by pathogenic variants (strains VIB, VIC, V3A). However, there is no evidence that the non-pathogenic variants of Maclean \& Scott (I974) or Williams \& Hartley (197I) are different in ploidy to the pathogenic strains. For example, strain v2A (non-pathogenic) produced the only observed example of anastomosis associated with dikaryotization.

Somatic diploidy in other rust fungi. The view that some rusts may exist as somatic diplophases was advanced in 1926, probably for the first time, by Dodge (I929), who cited work on short-cycled species of Kunkelia nitens and Endophyllum euphorbiae-sylvaticae. Dodge's conclusions were based on the relative sizes of spores and spore nuclei during germination of aeciospores of naturally occurring monokaryotic and dikaryotic isolates of each species: the monokaryotic strain of $K$. nitens appeared to be haploid, whilst the monokaryotic strain of $E$. euphorbiae-sylvaticae appeared to be diploid.

Dodge put the above point of view just prior to publication of the experiments of Craigie $(1927 a, b)$, which explained the sexuality of the rust fungi without the necessity to propose a somatic diplophase. Perhaps for this reason, the idea of an extended diplophase in rusts disappeared from the literature until the current work on axenic cultures. The alternative view that all monokaryotic rusts which produce spore forms typical of the dikaryophase are haploid, was put forward most forcibly by Buller (1950), who cited work on several rusts. Thus, Buller (I950) believed that aberrant monokaryotic strains of $P$. graminis tritici produced by Newton \& Johnson (1940) were haploid; this interpretation is now questionable.

In his extensive studies on the axenic culture of Gymnosporangium juniperi-virginianae, it is interesting that Cutter (1959, 1960) obtained monokaryotic cultures from material that was originally dikaryotic. However, unlike the current work on $\boldsymbol{P}$. graminis, Cutter's strains produced fruiting structures characteristic of the haplophase (see also Scott \& Maclean, 1969) and it appears that Cutter's monokaryons were haploid.

The parasexual cycle in fungi provides a means of genetic recombination via vegetative diploid nuclei (Roper, 1966). Somatic hybridization experiments on rusts have resulted in the formation of new strains which could not be accounted for by simple nuclear exchange (e.g. Watson \& Luig, 1958; Bridgmon, 1959; Ellingboe, 196r; Sharma \& Prasada, 1969; Bartos, Fleischmann, Samborski \& Shipton, 1969). Although parasexual mechanisms have been suggested as a way of explaining these phenomena, there has been no success in attempts 
to isolate a diploid strain of a rust by somatic hybridization experiments (cf. Little \& Manners, I969a, $b$; Bartos et al. 1969). The present investigation suggests that the onset and duration of the diplophase in rust fungi should be re-examined, particularly in those rusts which are capable of a high incidence of somatic variation when strains are mixed, and in naturally occurring rusts in which fruiting structures characteristic of the dikaryophase (aeciospores, uredospores, teliospores) are produced by an apparently unfertilized, monokaryotic mycelium.

We are grateful to Professor P. W. Brian for support, Dr P. G. Williams for discussions, and Dr C. E. Caten for criticism of the manuscript. This work was supported in part by the University of Cambridge (for I.C.T.), the Australian Research Grants Committee, and the Wheat Industry Research Council of Australia.

\section{REFERENCES}

Bartos, P., Fleischmann, G., Samborski, D. J. \& Shipton, W. A. (1969). Studies on asexual variation in the virulence of oat crown rust, Puccinia coronata f. sp. avenae, and wheat leaf rust, Puccinia recondita. Canadian Journal of Botany 47, 1383-1387.

Bridgmon, G. H. (1959). Production of new races of Puccinia graminis var. tritici by vegetative fusion. Phytopathology 49, 386-388.

Brown, A. M. (1940). The sexual behaviour of several plant rusts. Canadian Journal of Research 18 C, 1 8-25.

Buller, A. H. R. (1950). Researches on Fungi, vol. 7. Toronto: University of Toronto Press (for Royal Society of Canada).

ClutTERBUCK, A. J. (1969). Cell volume per nucleus in haploid and diploid strains of Aspergillus nidulans. Journal of General Microbiology 55, 291-299.

CraigiE, J. H. (1927a). Experiments on sex in rust fungi. Nature, London 120, II 6-I 17.

CraigIE, J. H. (1927b). Discovery on the function of the pycnia of the rust fungi. Nature, London 120, 765767.

CUTTER, V. M., JUn. (1959). Studies on the isolation and growth of plant rusts in host tissue cultures and upon synthetic media. I. Gymnosporangium. Mycologia 51, 248-295.

CUTTER, V. M., JUN. (c. 1960). Studies on the isolation and growth of various plant rusts in host tissue culture and upon synthetic media. Unpublished manuscript provided posthumously by Dr Lois Cutter.

DAY, A. W. (1972). Genetic implications of current models of somatic nuclear division in fungi. Canadian Journal of Botany 50, I337-1 347.

DAY, A. W. \& Jones, J. K. (1972). Somatic nuclear division in the sporidia of Ustilago violacea. I. Acetic orcein staining. Canadian Journal of Microbiology 18, 663-670.

DoDGe, B. O. (1929). Cytological evidence bearing on the sexuality and origin of life cycles in the Uredinae. Proceedings of the International Congress of Plant Science, Ithaca N.Y., 1926, vol. 2, 175I-1 766.

EluingBoe, A. H. (1961). Somatic recombination in Puccinia graminis var. tritici. Phytopathology 51, 13-15.

ElliNGBOE, A. H. (1964). Somatic recombination in dikaryon K of Schizophyllum commune. Genetics 49, 247-25I.

ESSER, K. \& KUENEN, R. (1967). Genetics of Fungi. New York: Springer-Verlag.

IshitAN, C., UchidA, K. \& IKEDA, Y. (1956). The relation of DNA content to cell size in Aspergillus. Experimental Cell Research 10, 737-740.

KÄFER, E. (196I). The process of spontaneous recombination in vegetative nuclei of Aspergillus nidulans. Genetics 46, 1581-1609.

LAMB, H. (1961). An Elementary Course of Infinitesimal Calculus, 3rd edn, p. 247. Cambridge: Cambridge University Press.

LitTLE, R. \& MANNERS, J. G. (I969a). Somatic recombination in yellow rust of wheat (Puccinia striiformis). I. The production and possible origin of two new physiological races. Transactions of the British Mycological Society 53, $25 \mathrm{I}-258$.

LITTLE, R. \& MANNERS, J. G. (1969b). Somatic recombination in yellow rust of wheat (Puccinia striiformis). II. Germ tube fusions, nuclear number, and nuclear size. Transactions of the British Mycological Society $53,259-267$. 
McGinnis, R. C. (I953). Cytological studies of chromosomes of rust fungi. I. The mitotic chromosomes of Puccinia graminis. Canadian Journal of Botany 31, 522-526.

MACLEAN, D. J. (197I). Studies on axenic cultures of the wheat stem rust fungus. Ph.D. thesis, University of Queensland, Australia.

MaClean, D. I (1974). Cultural and nutritional studies on variant strains of the wheat stem rust fungus. Transactions of the British Mycological Society 62, 333-349.

MACleAN, D. J. \& ScotT, K. J. (I970). Variant forms of saprophytic mycelium grown from uredospores of Puccinia graminis f. sp. tritici. Journal of General Microbiology 64, 19-27.

Maclean, D. J. \& Scotr, K. J. (1974). Pathogenicity of variant strains of the wheat stem rust fungus isolated from axenic culture. Canadian Journal of Botany 52, $201-207$.

Maclean, D. J., SCOTT, K. J. \& TOMmerup, I. C. (I97I). A uninucleate wheat-infecting strain of the stem rust fungus isolated from axenic cultures. Journal of General Microbiology 65, 339-342.

Newton, M. \& Johnson, T. (1940). Variation and hybridization in Puccinia graminis. 3rd International Congress for Microbiology, New York, 1939, Report of Proceedings, p. 544.

Robinow, C. F. \& CATEN, C. E. (1969). Mitosis in Aspergillus nidulans. Journal of Cell Science 5, 403-43I.

ROPER, J. A. (1966). Mechanisms of inheritance. III. The parasexual cycle. In The Fungi, an Advanced Treatise, vol. 2, pp. 589-617. Edited by G. C. Ainsworth and A. S. Sussman. New York and London: Academic Press.

Sargent, J. A., Tommerup, I. C. \& Ingram, D. S. (1973). The penetration of a susceptible lettuce variety by the downy mildew fungus Bremia lactucae Regel. Physiological Plant Pathology 3, 23 I-239.

ScotT, K. J. \& Maclean, D. J. (1969). Culturing of rust fungi. Annual Review of Phytopathology 7, $123-146$.

Sharma, S. K. \& Prasada, R. (1969). Production of new races of Puccinia graminis var, tritici from mixtures of races on wheat seedlings. Australian Journal of Agricultural Research 20, 981 -985 .

Tinline, R. D. \& MACNeILl, B. H. (1969). Parasexuality in plant pathogenic fungi. Annual Review of Phytopathology 7, 147-1 70.

TOMmerup, I. C. \& IngRam, D. S. (1971). The life-cycle of Plasmodiophora brassicae Woron. in Brassica tissue cultures and in intact roots. New Phytologist 7o, 327-332.

Tommerup, I. C. \& LANGdon, R. F. N. (1969). Studies of Cintractia axicola. I. Development of the sorus. Australian Journal of Botany 17, 25-29.

Watson, I. A. \& LuIG, N. H. (1958). Somatic hybridisation in Puccinia graminis var. tritici. Proceedings of the Linnean Society of New South Wales 83, I90-195.

Williams, P. G. (I971). A new perspective of the axenic culture of Puccinia graminis $\mathrm{f}$. sp. tritici from uredospores. Phytopathology 6r, 994-1002.

Williams, P. G. \& Hartley, M. J. (I97I). Occurrence of diploid lines of Puccinia graminis tritici in axenic culture. Nature New Biology 229, I $81-182$.

Williams, P. G., Scott, K. J., KuHL, J. L. \& Maclean, D. J. (I967). Sporulation and pathogenicity of Puccinia graminis f. sp. tritici grown of an artificial medium. Phytopathology 57, 326-327. 